\title{
Article \\ Monitoring Olive Oil Mill Wastewater Disposal Sites Using Sentinel-2 and PlanetScope Satellite Images: Case Studies in Tunisia and Greece
}

\author{
Wissal Issaoui ${ }^{1,2, *}$, Dimitrios D. Alexakis ${ }^{3}$ (D) , Imen Hamdi Nasr ${ }^{1,2}$, Athanasios V. Argyriou ${ }^{3}$, \\ Evangelos Alevizos ${ }^{3}$, Nikos Papadopoulos ${ }^{3}$ id and Mohamed Hédi Inoubli ${ }^{2}$
}

Citation: Issaoui, W.; Alexakis, D.D.; Nasr, I.H.; Argyriou, A.V.; Alevizos,

E.; Papadopoulos, N.; Inoubli, M.H.

Monitoring Olive Oil Mill

Wastewater Disposal Sites Using Sentinel-2 and PlanetScope Satellite Images: Case Studies in Tunisia and Greece. Agronomy 2022, 12, 90.

https://doi.org/10.3390/

agronomy12010090

Academic Editor: Enrico

Borgogno Mondino

Received: 22 November 2021

Accepted: 27 December 2021

Published: 30 December 2021

Publisher's Note: MDPI stays neutral with regard to jurisdictional claims in published maps and institutional affiliations.

Copyright: (C) 2021 by the authors. Licensee MDPI, Basel, Switzerland. This article is an open access article distributed under the terms and conditions of the Creative Commons Attribution (CC BY) license (https:// creativecommons.org/licenses/by/ $4.0 /)$
1 Department of Earth Sciences, Faculty of Sciences of Bizerte, Carthage University, Jarzouna, Bizerte 7021, Tunisia; imenhamdi79@yahoo.fr

2 UR-GAMM, Faculty of Sciences of Tunis, University of El Manar, Tunis 2092, Tunisia; mh.inoubli@gmail.com

3 Laboratory of Geophysical-Satellite Remote Sensing and Archaeoenvironment, Institute for Mediterranean Studies, Foundation for Research and Technology-Hellas (FORTH), 74100 Rethymno, Greece; dalexakis@ims.forth.gr (D.D.A.); nasos@ims.forth.gr (A.V.A.); ealevizos@ims.forth.gr (E.A.); nikos@ims.forth.gr (N.P.)

* Correspondence: wilala27972172@gmail.com
Abstract: Mediterranean countries are known worldwide for their significant contribution to olive oil production, which generates large amounts of olive mill wastewater (OMW) that degrades land and water environments near the disposal sites. OMW consists of organic substances with high concentrations of phenolic compounds along with inorganic particles. The aim of this study is to assess the effectiveness of satellite image analysis techniques using multispectral satellite data with high (PlanetScope, $3 \times 3 \mathrm{~m}$ ) and medium (Sentinel-2, $10 \times 10 \mathrm{~m}$ ) spatial resolution to detect Olive Mill Wastewater (OMW) disposal sites, both in the SidiBouzid region (Tunisia) and in the broader Rethymno region on the island of Crete, (Greece). Documentation of the sites was carried out by collecting spectral signatures of OMW at temporal periods. The study integrates the application of a variety of spectral vegetation indices (VIs), such as the Normalized Difference Vegetation Index (NDVI), in order to evaluate their efficiency in detecting OMW disposal areas. Furthermore, a set of image-processing methods was applied on satellite images to improve the monitoring of OMW ponds including the false-color composites (FCC), the Principal Component Analysis (PCA), and image fusion. Finally, different classification algorithms, such as the ISODATA, the maximum likelihood (ML), and the Support Vector Machine (SVM) were applied to both satellite images in order to assist in the overall approach to effectively detect the sites. The results obtained from different approaches were compared, evaluating the efficiency of Sentinel-2 and PlanetScope images to detect and monitor OMW disposal areas under different morphological environments.

Keywords: olive mill wastewater (OMW); disposal sites; remote sensing; spectral signature; indices; classification

\section{Introduction}

There are about 750 million productive olive trees worldwide, with 735 million of them being located in the Mediterranean region, contributing more than $97 \%$ of the olive oil world's production. The four major olive oil producers around the world, are Spain (36\%), Italy (24\%), Greece at (17\%) and Tunisia (8.5\%) [1]. However, the olive oil production cycle generates large amounts of solid wastes and wastewater that pose a significant environmental risk due to their high phytotoxicity resulting from increased concentrations of inorganic constituents [2-4]. Uncontrolled disposal of olive mill wastewater in ponds can result in soil contamination caused by leachate of wastewater with high biochemical oxygen (40-95 g/L) and chemical oxygen demand (50-180 g/L), leading to phytotoxicity due to high concentration in phenolic compounds [3]. 
Nevertheless, a few studies have treated the negative effects of these hazardous wastes on soil microbes [5] and water environments [6,7]. OMW disposal sites cause important environmental problems, such as the odd smell due to evaporation of ammonia and the infiltration of the organic and inorganic materials that flow in different levels of soil, eventually reaching the ground water [8]. For this reason, Bailey et al. [9] indicated the vital necessity to have specific strategies in order to resolve and control OMW sites.

Remote sensing technologies are efficient methods for monitoring and mapping land cover and land use changes [10,11]. Earth Observation (EO) data have been used to monitor and map land use to meet the expanding requests for fundamental human needs and welfare [11-13]. In this concept, several studies have employed satellite images for monitoring environmental parameters, especially water bodies, that are affected mainly by severe anthropogenic activities [14,15]. In the recent past, satellite remote sensing integrated with a compilation of in situ spectral signature libraries have been also utilized to identify and monitor OMW disposal sites [4,16].

This work focuses on two different sites in the Mediterranean region (Tunisia and Greece) that face significant environmental pollution issues due to unsupervised disposal of OMW. The goal of this study is to assess the capability of remote sensing data to identify and map OMW disposal sites through the application of various established image-processing techniques applied in different satellite products, such as Sentinel-2 and PlanetScope.

\section{Materials and Methods}

\subsection{Study Areas and Satellite Imagery}

Olive groves have covered extended areas in coastal and semi-mountainous areas in Crete since the last quarter of the 20thcentury [17]. Crete is known for intensive agricultural activities where the olive industry represents a major component of its economy (Figure 1a). More than 1000 OMW ponds are located on the island and had been detected in the past using the Global Navigation Satellite Systems (GNSS) and the Geographical Information Systems (GIS) [4].

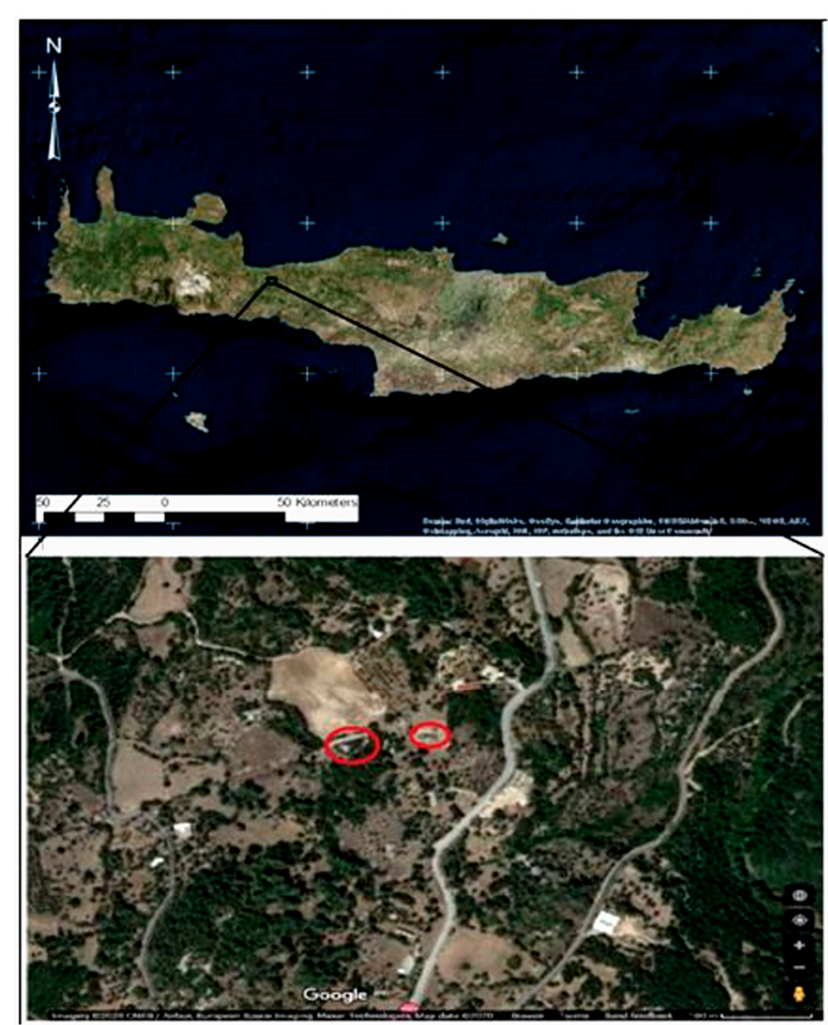

(a)

Figure 1. Cont. 


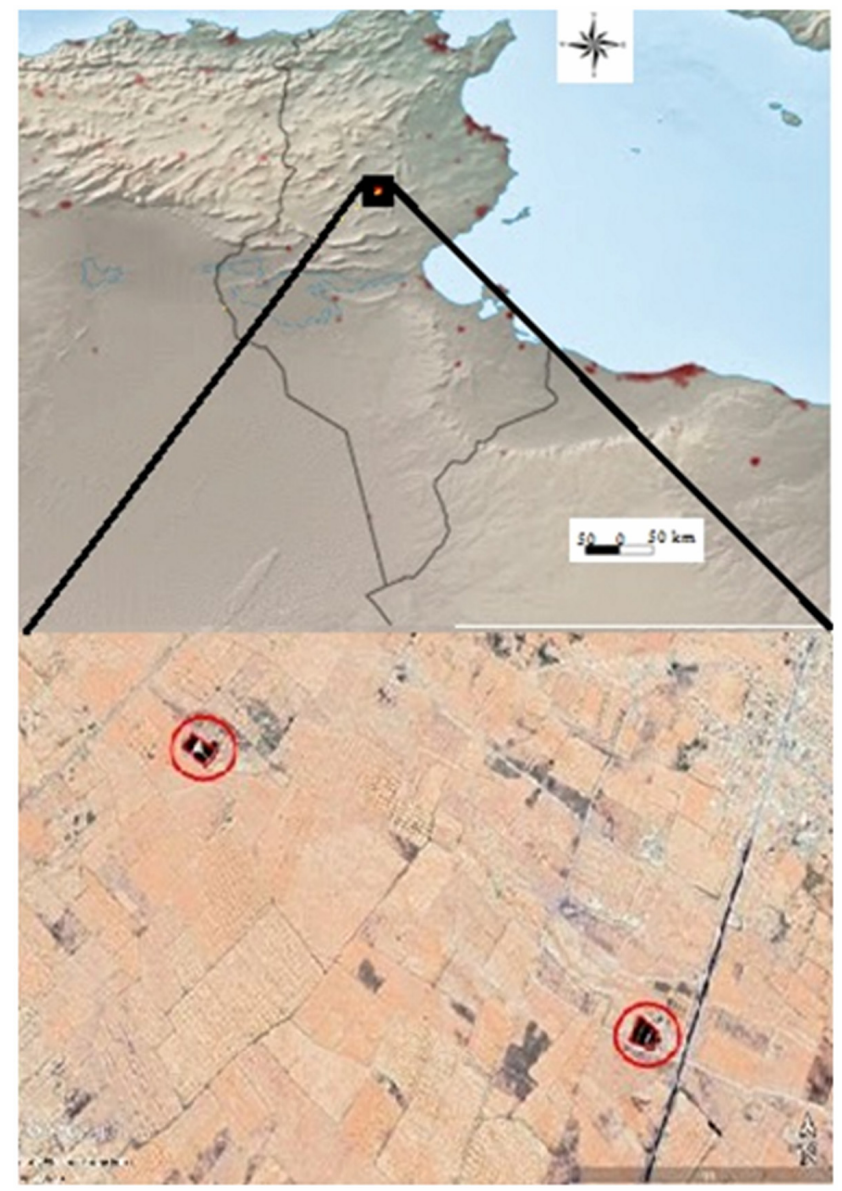

(b)

Figure 1. (a) Greek study areas, (red circle: OMW disposal areas), (b) Tunisian study areas, (red circle: OMW disposal areas).

The second study area is located in the middle part of the Tunisian republic (Figure 1b). It has been chosen as a study area for its considerable contribution to the cultivation of olives and production of olive oil in the country [18]. This region is the fourth in Tunisia in terms of number of mills, with mill-density around 1 mill/100 $\mathrm{km}^{2}$. SidiBouzid is ranked as the second place in Tunisia in terms of annual oil production, totaling to about $90,000 \mathrm{~m}^{3}$ [19]. The olive groves have expanded constantly, covering $36 \%$ of the total area $(254,245$ ha in total), while the climate in the region is arid.

A number of medium- and high-resolution satellite images were analyzed in this study. Particularly, eight Sentinel-2 (L1C) images and eight PlanetScope images of the SidiBouzidand Rethymno areas were obtained and evaluated for their efficiency in OMW monitoring (Tables 1 and 2). The images' temporal acquisition period consisted of February, April, August, and October 2020.

The European Space Agency (ESA) launched, in 2015 and 2017, two satellites (S-2A and $\mathrm{S}-2 \mathrm{~B})$ for the Sentinel-2 mission, comprising the second environmental monitoring plan for the mission of Copernicus [20]. The Multi-Spectral Instrument (MSI) sensor that is embedded inboth satellites provides a spatial resolution of $10-60 \mathrm{~m}$, according to band wavelength. The Sentinel-2 mission provides open access to image data for the global land surface with a six-day revisit period. For the needs of the study, Sentinel-2 (L1C)data were used.

The PlanetScope mission was launched in November 2018 and its constellation of approximately 130 satellites covers extensive surface areas on a daily basis (200 million $\mathrm{km}^{2} /$ day). PlanetScope imagery is characterized by improved spectral and spatial resolu- 
tions, (up to $3 \mathrm{~m}$ ), offering an increased applicability in temporal coverage of the Earth's surface with high spatial resolution.

Table 1. Satellite sensor specifications.

\begin{tabular}{cccc}
\hline Bands & Description & Central Wavelength $(\boldsymbol{\mu m})$ & Resolution $(\mathbf{m})$ \\
\hline Sentinel-2 & Coastal aerosol & 0.443 & \\
Band 1 & Blue & 0.490 & 60 \\
Band 2 & Green & 0.560 & 10 \\
Band 3 & Red & 0.665 & 10 \\
Band 4 & Vegetation Red Edge & 0.705 & 20 \\
Band 5 & Vegetation Red Edge & 0.740 & 20 \\
Band 6 & Vegetation Red Edge & 0.783 & 20 \\
Band 7 & NIR & 0.842 & 10 \\
Band 8 & Vegetation Red Edge & 0.865 & 20 \\
Band 8A & Water vapor & 0.945 & 60 \\
Band 9 & SWIR-Cirrus & 1.375 & 60 \\
Band 10 & SWIR & 1.610 & 20 \\
Band 11 & SWIR & 2.190 & 20 \\
Band 12 & & & 3 \\
Planetscope & Blue & $0.455-0.515$ & 3 \\
Band 1 & Green & $0.500-50.90$ & 3 \\
Band 2 & Red & $0.590-0.670$ & 3 \\
Band 3 & NIR & $0.780-0.860$ & 3 \\
Band 4 & &
\end{tabular}

Table 2. Satellite imageacquisition dates.

\begin{tabular}{lll}
\hline & Tunisian Study Area & Greek Study Area \\
\hline Sentinel-2 images & 25 February 2020 & 25 February 2020 \\
& 28 April 2020 & 17 April 2020 \\
& 26 August 2020 & 18 August 2020 \\
02 October 2020 & 02 October 2020 \\
PlanetScope images & 25 February 2020 & 25 February 2020 \\
& 28 April 2020 & 17 April 2020 \\
& 25 August 2020 & 18 August 2020 \\
& 02 October 2020 & 03 October 2020 \\
\hline
\end{tabular}

The last generation of PlanetScope is presently in orbit and yields restricted numbers of images with five spectral bands (Blue, Green, Red, NIR, and Red Edge). For the needs of the study, Level 3B Ortho Scene data were incorporated. The overall hierarchical structure of the methodology is described in Figure 2.

\subsection{Satellite Imagery Processing Techniques}

In this study, several data-preparation steps were implemented in order to convert the initial satellite images into useful descriptive layers that maximize the identification of OMW ponds during the image analysis process.

Concerning the Sentinel-2 L1C data, the digital number (DN) was converted first to radiance and then to reflectance. Moreover, atmospheric correction was applied to Sentinel-2images. Darkest pixel (DP) is a prompt and precise atmospheric correction technique that is applied through the application of dark and non-variant targets detected in satellite images [21,22]. In our study, lakes and dams were utilized as non-variant targets for that purpose. Concerning Planetscope imageries, the Level 3B Ortho Scene concerns orthorectified reflectance data that are atmospherically corrected using 6SV2.1 radiative transfer code and MODIS NRT data. 


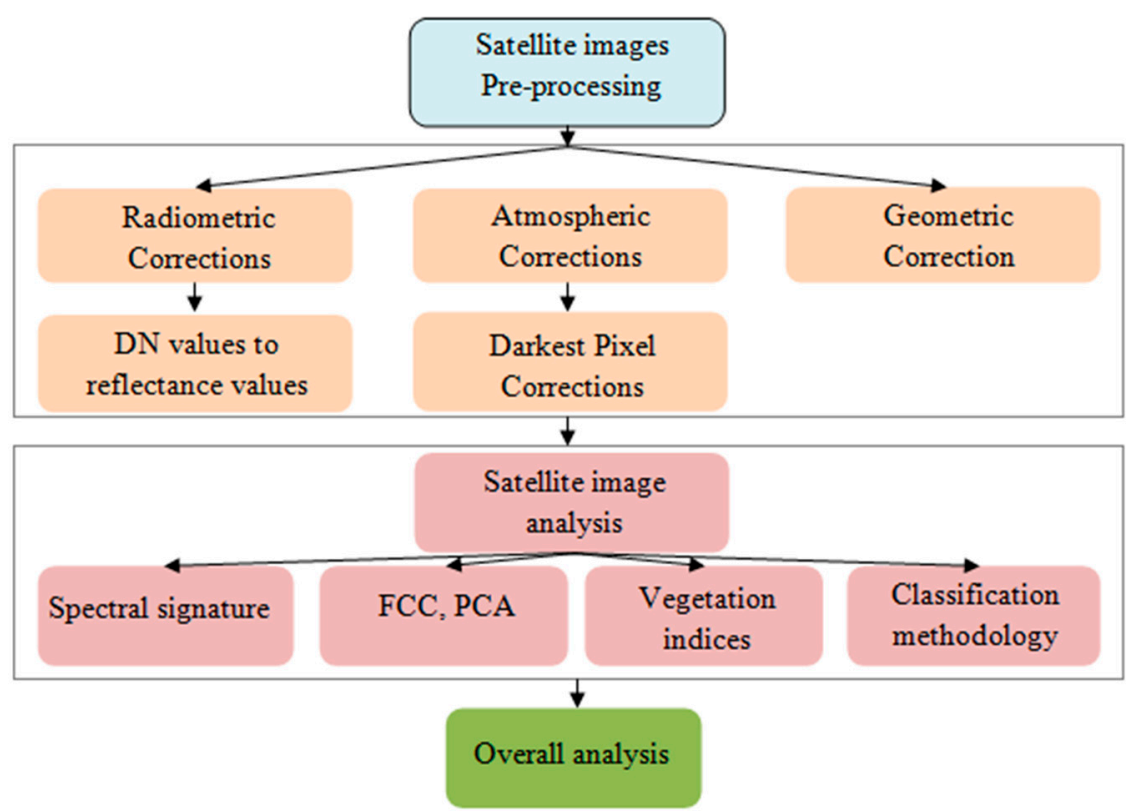

Figure 2. Hierarchical structure of methodology and satellite image data processing.

\subsection{False-Color Composites}

The selection of the optimum band combination for detecting OMW ponds was carried out using various False-Color Composites (FCC). Thus, the optimum index factor (OIF) was calculated to find out the best combination of three bands via the testing of three correlation coefficients and standard deviations according to Equation (1) [23].

$$
\mathrm{OIF}=\frac{\sum_{i=1}^{3} S D i}{\sum_{j=1}^{3} A C C j}
$$

where $S D i$ is the standard deviation of band $I$ and $A C C j$ is the absolute value of the correlation coefficient linking any two of the feasible pairs, $j$.

\subsection{Principal Component Analysis}

Principal component analysis (PCA) was applied to all Sentinel-2 and PlanetScope datasets to improve the overall interpretation of satellite images in terms of OMW detection. PCA is an image analysis technique that transforms originally correlated bands into a set of uncorrelated principal components, organized in a descending scale referring to the degree of the original contained information [24]. This technique was implemented to optimize the size of the dataset (i.e., the dimensionality of the original bands) by combining the information collected from the original bands into the reduced number of the final principal components.

\subsection{Spectral Signatures Collection}

Spectral signature collection is an essential method used to monitor OMW during different time periods. In this context, band spectral signatures were collected for the two sensors, analyzed for their sensitivity to detect OMW ponds in both study areas for different temporal periods, and finally, were statistically compared. Specifically, to assess spectral pair bands of both satellite images (Sentinel-2 and PlanetScope)in terms of their minimum spectral correlation, a Euclidean distance computation was calculated for all the spectral signatures [4], as shown below (Equation (2)).

$$
\mathrm{D}(\mathrm{x}, \mathrm{y})=\sqrt{ } \sum_{\mathrm{i}=1}^{\mathrm{n}}(\mathrm{xi}-\mathrm{yi})^{2}
$$


where $x i$ and yi are two different points.

At this step, a proximity matrix was developed for all spectral signatures in order to measure the spectral vectors of every channel at different dates (Tables 3 and 4).

Table 3. Euclidean distance using Sentinel-2; (a): Tunisian study areas, (b): Greek study areas.

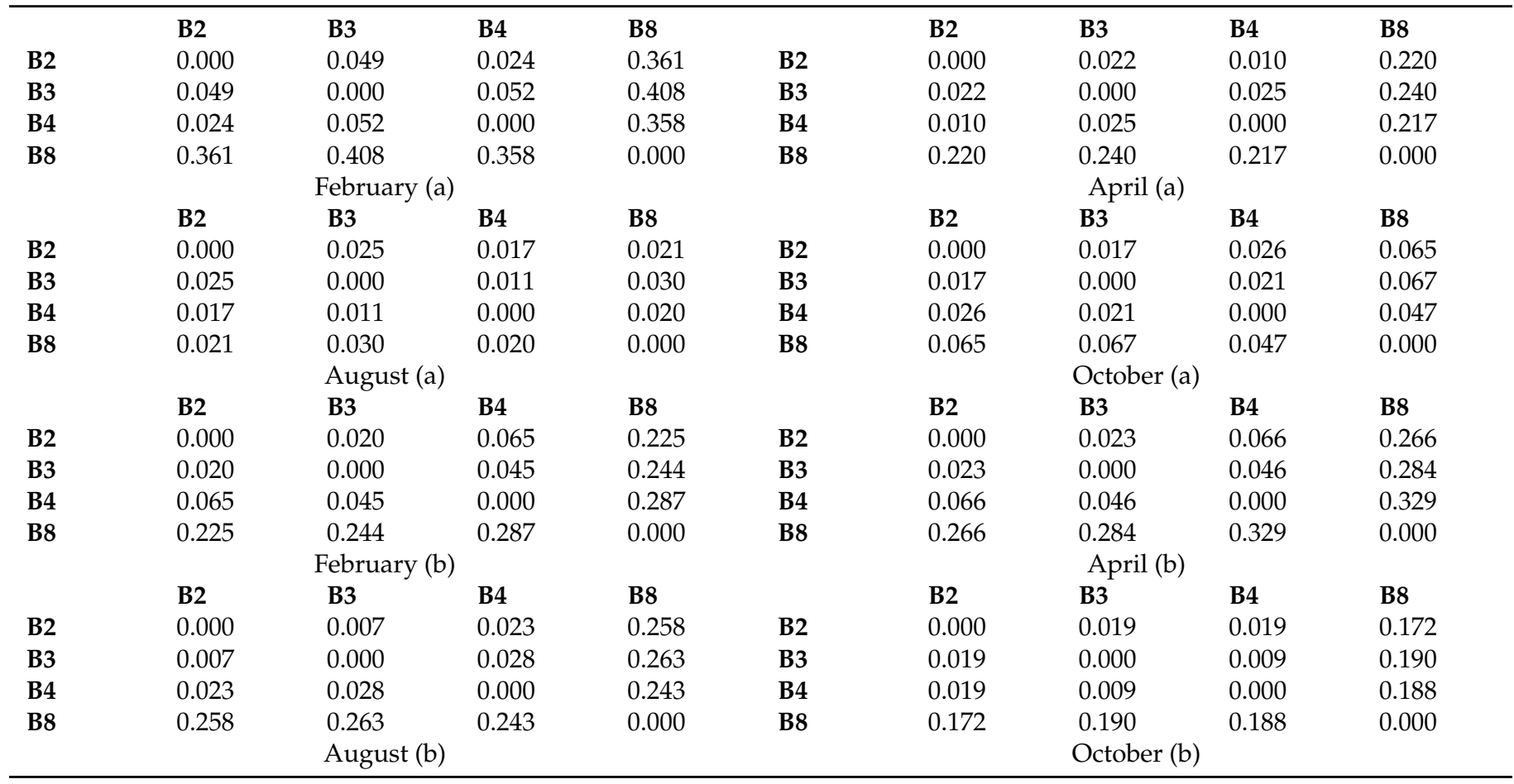

Table 4. Euclidean distance using PlanetScope; (a): Tunisian study areas, (b): Greek study areas.

\begin{tabular}{|c|c|c|c|c|c|c|c|c|c|}
\hline & B1 & B2 & B3 & B4 & & B1 & B2 & B3 & B4 \\
\hline B1 & 0.000 & 0.062 & 0.158 & 0.559 & B1 & 0.000 & 0.037 & 0.114 & 0.394 \\
\hline B2 & 0.062 & 0.000 & 0.098 & 0.499 & B2 & 0.037 & 0.000 & 0.077 & 0.358 \\
\hline B3 & 0.158 & 0.098 & 0.000 & 0.401 & B3 & 0.114 & 0.077 & 0.000 & 0.284 \\
\hline \multirow[t]{3}{*}{ B4 } & 0.559 & 0.499 & 0.401 & 0.000 & B4 & 0.394 & 0.358 & 0.284 & 0.000 \\
\hline & & Februa & & & & & April & & \\
\hline & B1 & B2 & B3 & B4 & & B1 & B2 & B3 & B4 \\
\hline B1 & 0.000 & 0.085 & 0.160 & 0.299 & B1 & 0.000 & 0.066 & 0.134 & 0.229 \\
\hline B2 & 0.085 & 0.000 & 0.075 & 0.215 & B2 & 0.066 & 0.000 & 0.069 & 0.164 \\
\hline B3 & 0.160 & 0.075 & 0.000 & 0.140 & B3 & 0.134 & 0.069 & 0.000 & 0.096 \\
\hline \multirow[t]{3}{*}{ B4 } & 0.299 & 0.215 & 0.140 & 0.000 & B4 & 0.229 & 0.164 & 0.096 & 0.000 \\
\hline & & Augus & & & & & Octob & & \\
\hline & B1 & B2 & B3 & B4 & & B1 & B2 & B3 & B4 \\
\hline B1 & 0.000 & 0.022 & 0.022 & 0.236 & B1 & 0.000 & 0.024 & 0.032 & 0.234 \\
\hline B2 & 0.022 & 0.000 & 0.002 & 0.214 & B2 & 0.024 & 0.000 & 0.009 & 0.210 \\
\hline B3 & 0.022 & 0.002 & 0.000 & 0.215 & B3 & 0.032 & 0.009 & 0.000 & 0.203 \\
\hline \multirow[t]{3}{*}{ B4 } & 0.236 & 0.214 & 0.215 & 0.000 & B4 & 0.234 & 0.210 & 0.203 & 0.000 \\
\hline & & Februa & & & & & April & & \\
\hline & B1 & B2 & B3 & B4 & & B1 & B2 & B3 & B4 \\
\hline B1 & 0.000 & 0.022 & 0.038 & 0.273 & B1 & 0.000 & 0.037 & 0.063 & 0.227 \\
\hline B2 & 0.022 & 0.000 & 0.017 & 0.251 & B2 & 0.037 & 0.000 & 0.025 & 0.190 \\
\hline B3 & 0.038 & 0.017 & 0.000 & 0.235 & B3 & 0.063 & 0.025 & 0.000 & 0.165 \\
\hline \multirow[t]{2}{*}{ B4 } & 0.273 & 0.251 & 0.235 & 0.000 & B4 & 0.227 & 0.190 & 0.165 & 0.000 \\
\hline & & Augus & & & & & Octobe & & \\
\hline
\end{tabular}




\subsection{Spectralindices}

Efficient, remote-sensing monitoring of OMW disposal sites merely depends on the surrounding land cover [25]. Numerous OMW areas are established at remote locations and are encompassed by vegetation barriers to ensure that they are secured, roofed, and that they prevent bad odors and visual interruption from adjoining settlements. Thus, various spectral indices were applied to monitor the OMW and increase the spectral difference between OMW areas and adjoining vegetation surfaces. NDVI represents the normalized ratio of red and near-infrared band Equation (3).

$$
N D V I=\frac{\text { Red band }- \text { NIR band }}{\text { Red band }+ \text { NIR band }}
$$

Besides NDVI, the NDWI (Normalized Difference Water Index) (Equation (4)) has been calculated as well, following the normalized ratio between green and near-infrared reflectance for both satellite images in order to detect the liquid part of waste areas. Equation (4) has been developed by Mc Feeters [26] in order to identify the water bodies in wetland areas:

$$
\text { NDWI }=\frac{\text { Green band }- \text { NIR band }}{\text { Green band }+ \text { NIR band }}
$$

In addition to the NDVI and NDWI, seven other spectral indices were applied for evaluating their efficiency in enhancing the contrast of the OMW disposal areas with their adjacent areas by applying those in medium- and high-resolution satellite imagery. Initially, the simple ratio (SR) was applied; it combines the red and the near-infrared reflectance data to detect biophysical surfaces [27]. The Renormalized Difference Vegetation Index (RDVI) was applied to linearize the relationship between the index and biophysical parameters. This index was based on the slope of constant index lines in the NIR and red reflectance and it was developed for estimating distances between lines, realizing the parallel lines to each other [28]. Huete [29] developed both the NDVI and the Soil Adjusted Vegetation Index (SAVI) in order to reduce the influence of soil characteristics in the VIs satellite images. A set of developments have been applied to the soil-adjusted vegetation index; the Modified Soil Adjusted Vegetation Index (MSAVI) proposed by Qi et al. [30]; and the Optimized Soil Adjusted Vegetation Index (OSAVI) by Rondeauxet al. [31]. The Difference Vegetation Index (DVI) was proposed by Richardson and Everitt [32] and the Enhanced Vegetation Index (EVI) was developed for incorporating the atmospheric resistance concepts and the background adjustment using feedback based on the NDVI algorithm [33]. EVI is considered to be a modified NDVI by improving the sensitivity of high biomass areas and enhancing the efficiency of vegetation reflectance as referred to atmospheric influence reduction and canopy background [34]. The equations of the spectral indices are analytically described in Table 5 .

\begin{tabular}{|c|c|c|}
\hline Indices & Equations & \\
\hline SR & NIR band & (5) \\
\hline RDVI & $\frac{\text { NIR band }- \text { Red band }}{\sqrt{(\text { NIR }} \text { band }+ \text { Red band })} ;$ & $(6)$ \\
\hline SAVI & $\frac{(1+\mathrm{L})(\text { Red band }-\mathrm{NIR} \text { band })}{(\mathrm{NIR} \text { band }+ \text { Red band }+\mathrm{L})}$ & $(7)$ \\
\hline MSAVI & $0.5 *((2 *$ NIR band +1$)-\sqrt{ }((2 *$ NIR band $) 2-8 *($ NIR band - Red band $))$ & $(8)$ \\
\hline OSAVI & $1.16 * \frac{\text { NIR band-Red band }}{\text { NIR band }+ \text { Red band }+0.16}$ & (9) \\
\hline DVI & NIR band - a $*$ Red band; & (10) \\
\hline EVI & $\mathrm{G} * \frac{\mathrm{NIR} \text { band }- \text { Red band }}{\text { NIR band }+(\mathrm{C} 1 * \text { Red band }-\mathrm{C} 2 * \text { Blue band })+\mathrm{F}} ;$ & $(11)$ \\
\hline
\end{tabular}

Table 5. Equations of different spectral indices used.

where the NIR band is reflectance in the NIR part of spectrum; the Red band is the reflectance in the red part of spectrum; the Blue band is the reflectance in the blue part of spectrum; $\mathrm{a}=0.96916, \mathrm{~L}=0.5$ [32]; $\mathrm{F}$ is a soil adjustment factor, and $\mathrm{C} 1$ and $\mathrm{C} 2$ are coefficients used to correct aerosol scattering in the red band using the blue band. In general, $\mathrm{G}=2.5, \mathrm{C} 1=6.0, \mathrm{C} 2=7.5$, and $\mathrm{F}=1$ [35]. 
Further analysis was implemented for evaluating the contrast of OMW disposal areas with areas in the vicinity; a sensitivity analysis parameter was calculated in order to measure the spectral optimization level of images by applying the vegetation indices to satellite images [4].Thus, two sets of spectral responses (OMW disposal areas and nonoccupied neighborhood areas) were calculated in order to measure the sensitivity analysis of vegetation indices (relative difference of the two patterns \%) using both sensors for different case studies and time periods.

\subsection{Image Classification Algorithms}

Both supervised and unsupervised algorithms were applied in order to assist in the effective monitoring of OMW sites. Initially, the ISODATA unsupervised classification algorithm was applied in order to group each pixel to a cluster according to the Euclidean distance parameter [36]. Additionally, satellite images were processed with the Maximum Likelihood (ML) classification algorithm [37]. ML classification is a widely-applied method in remote sensing that has shown increased performance in classifying datasets with a large number of classification variables [38-40]. In order to test an additional classification technique, the Support Vector Machine (SVM) was applied as well [41]. The main concept of the SVM algorithm is to determine a hyperplane that optimally separates two classes. The SVM algorithm is independent of data dimensionality [42], which is a key feature when using many spectral bands or when ancillary data are included in the classification process, as is the case of OMW [43]. Previous studies tested SVM and evaluated its performance using pixel-based image classification with very good results [44-47].

Both Sentinel-2 (acquired during February and August) and PlanetScope (acquired during February and August) images were processed for all study areas. The following image composites were incorporated in the classification: (a) Composite 1, using band2, band3, band 4 , and band 8 for Sentinel-2 and band1, band2, band3, and band 4 for PlanetScope, (b) Composite 2, using NDVI, NDWI, RGB, and PCA bands (first component applied for RGB-248 and RGB-234 for Sentinel-2 and PlanetScope, respectively) [4], and (c) Composite 3 , our proposed image composite obtained through the application of Principal Component Analysis (PCA) to RGB, NDVI, and NDWI layers.

\section{Results}

\subsection{False-Color Composites}

Figure 3 shows that the optimum band combination applied to enhance the OMW disposal areas was calculated using RGB-248 for Sentinel-2 images and RGB-234 for PlanetScope datasets. The higher value of the OIF was recorded for the images acquired during October for both study areas (Figure 3). Thus, those RGB composites were selected as optimal for being used in the further processing steps.

\subsection{PCA Analysis}

The results indicated that the PCA approach (Figure 4) improved the spectral contrast of the OMW ponds compared to their neighborhood terrain by detecting OMW places for the majority of cases and therefore increased the ability of Sentinel-2 and PlanetScope images to identify the OMW disposal sites.

\subsection{Spectral Signatures Collection}

The results indicated that thePlanetScope signature response was slightly higher than those of Sentinel-2 (Figure 5). However, both diagrams of spectral signature analysis show high reflectance values corresponding to their chlorophyll content through the NIR band, that is, band 4 in PlanetScope and band 8 in Sentinel-2. PlanetScope can provide more discrete details in terms of reflectance values of OMW disposal areas than the Sentinel2 imagery. In addition, it was proved that for images from both satellites, the higher sensitivity of OMW reflectance in NIR was indicated for images acquired during February when the olive wastes were exposed in the ponds. 
(a)

(c)

(e)

(g)
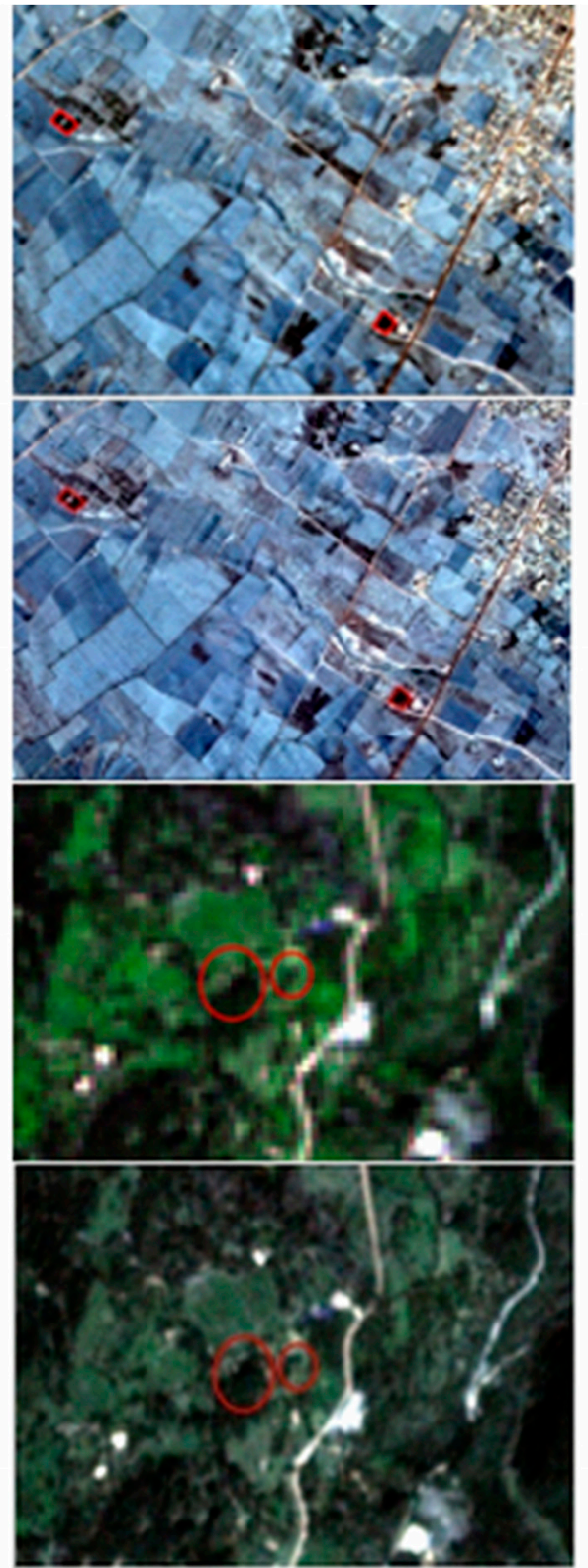
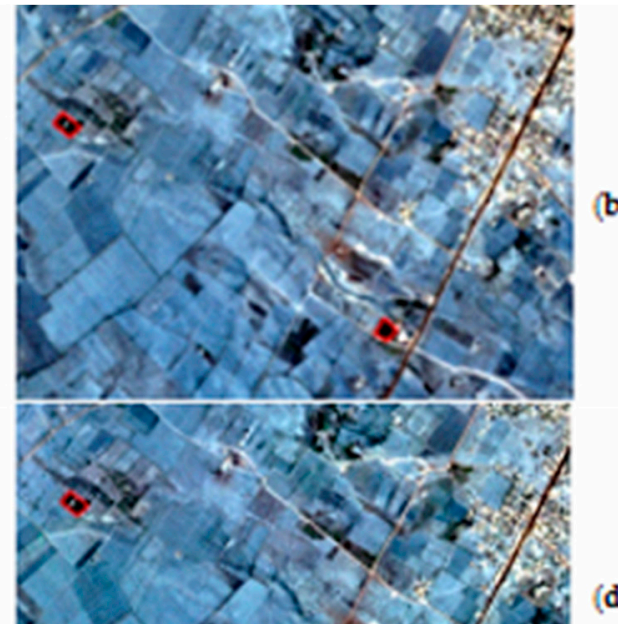

(d)

(b)
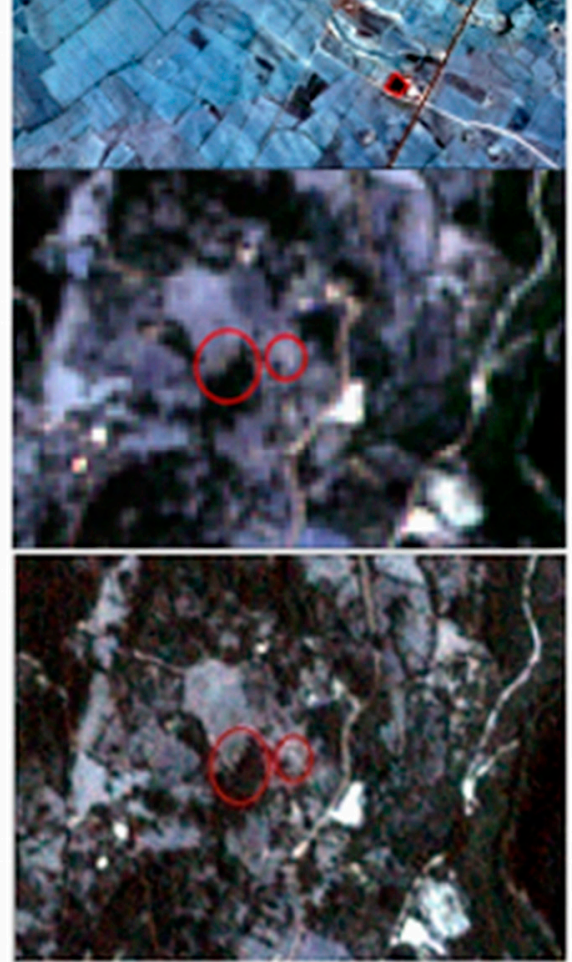

(h)

Figure 3. (a): Sentinel-2 RGB image (RGB-248) in 25/February/2020, Tunisian study areas, (b): Sentinel-2 RGB image (RGB-248) in 26/August/2020, Tunisian study areas, (c): PlanetScope RGB image (RGB-234) in 25/February/2020, Tunisian study areas, (d): PlanetScope RGB image (RGB-234) in 25/August/2020, Tunisian study areas, (e): Sentinel-2 RGB image (RGB-248) in 25/February/2020, Greek study area, (f): Sentinel-2 RGB image (RGB-248) in 18/August/2020, Greek study areas, (g): PlanetScope RGB image (RGB-234) in 25/February/2020, Greek study areas, (h): PlanetScope RGB image (RGB-234) in 18/August/2020, Greek study areas. The simple false-color composite fails to depict the OMW disposal areas efficiently for Greek study areas (indicated inside the red frame). 
(a)

(c)

(e)

(g)
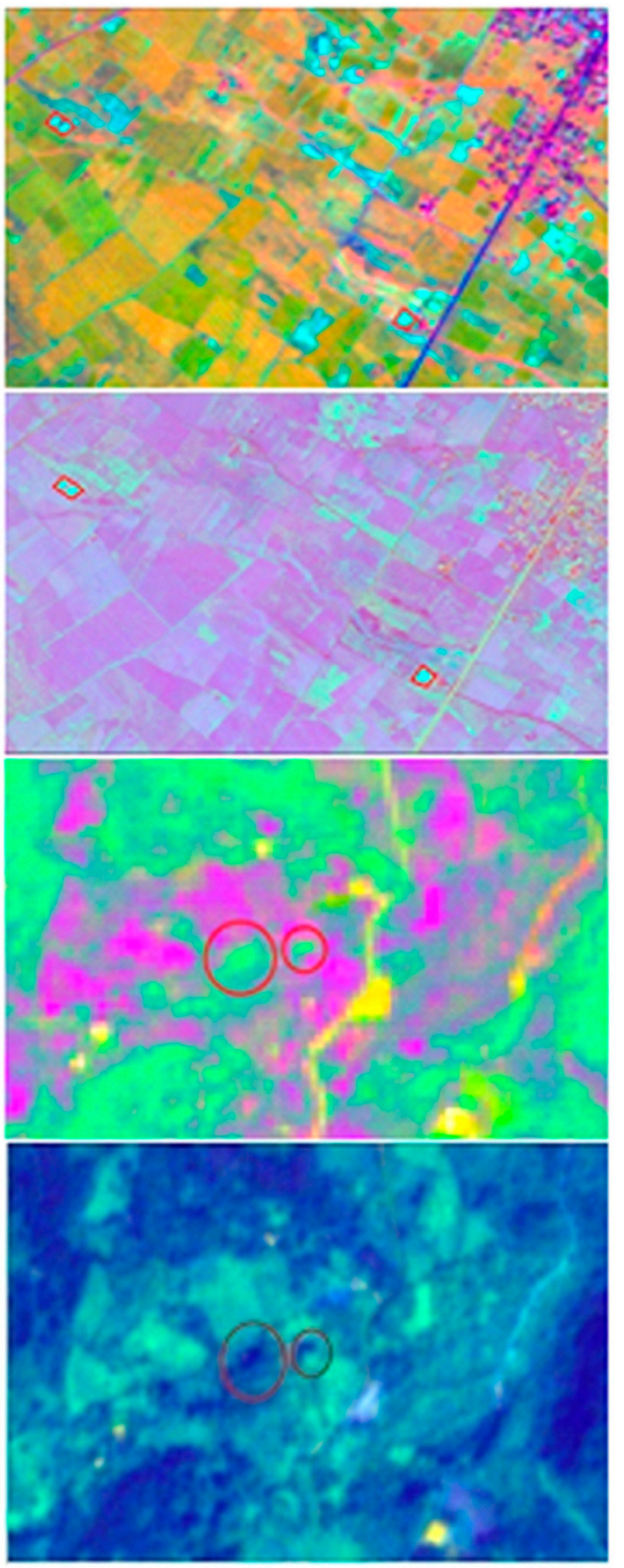

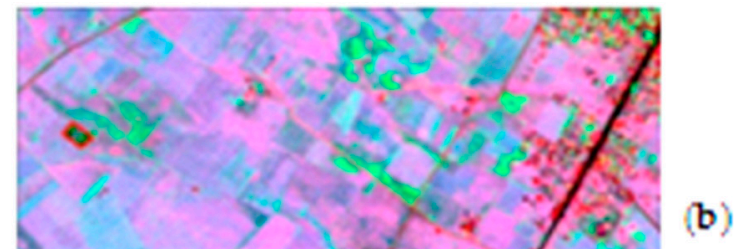

(b)

d)

(f)

(h)

Figure 4. Results of the application of PCA method to the image shown in Figure 3 (Sentinel-2 and PlanetScope, Tunisian and Greek study areas). (a): Sentinel-2 PCA composite (RGB-248 band 2, band 4, band8) in 25/February/2020, Tunisian study areas, (b): Sentinel-2 PCA composite (band 2, band 4, band8) in 26/August/2020, Tunisian study areas, (c): PlanetScope PCA composite (band 2, band 3, band4) in 25/February/2020, Tunisian study areas, (d): PlanetScope PCA composite (band 2, band 3, band4) in 25/August/2020, Tunisian study areas, (e): Sentinel-2 PCA composite (band 2, band 4, band8) in 25/February/2020, Greek study areas, (f): Sentinel-2 PCA composite (band 2, band 4, band8) in 18/August/2020, Greek study areas, (g): PlanetScope PCA composite (band 2, band 3, band4) in 25/February /2020, Greek study areas, (h): PlanetScope PCA composite (band 2, band 3, band4) in 18/August/2020, Greek study areas. 

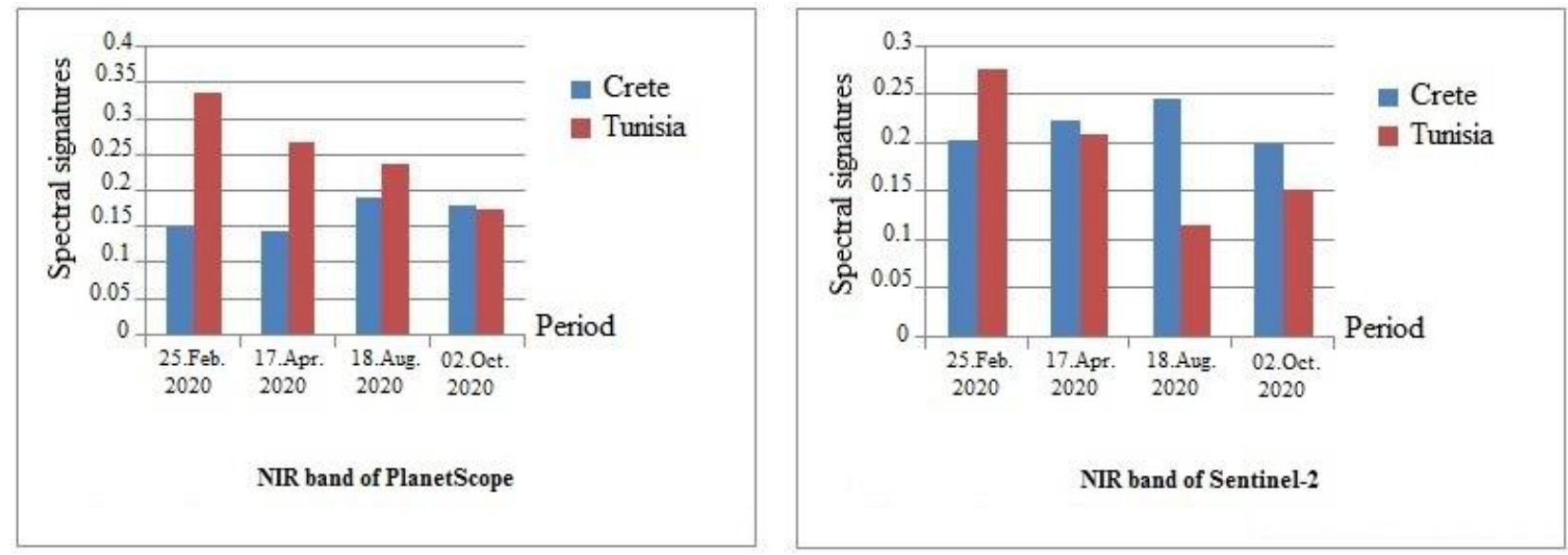

Figure 5. Spectral signature of OMW disposal areas.

The Euclidean distance results for Sentinel-2 showed that the most prominent spectral differences are between bands B3/B8 for both study areas. That is, the Green/NIR increases the sensitivity of these bands in detecting the chlorophyll. Concerning the PlanetScope data, the Euclidean distance revealed that the ratio between bands B1/B4 highlights the greatest spectral differences in both study areas in different time periods. This is identical to the results of Alexakis et al. [4], who analyzed the corresponding spectral difference that was detected in OMW sites between bands B5/B2 using Landsat-8.

$$
\begin{aligned}
& \mathrm{DI}_{\text {Sentinel-2 }}=\mathrm{f} \text { (Green band, NIR band) } \\
& \mathrm{DI}_{\text {PlanetScope }}=\mathrm{f} \text { (Blue band, NIR band) }
\end{aligned}
$$

Equations (12) and (13) were defined by Equations (14) and (15) through the normalization of the difference of spectral signatures of the two selected bands in order to optimize the contribution of detection indices in identifying OMW areas and to enhance the radiometric response of imagery.

$$
\begin{gathered}
\mathrm{DI}_{\text {Sentinel-2 }}=\frac{\text { NIRband }- \text { Greenband }}{\text { NIRband }+ \text { Greenband }} \\
\text { DI }_{\text {PlanetScope }}=\frac{\text { NIR band }- \text { Blue band }}{\text { NIR band }+ \text { Blue band }}
\end{gathered}
$$

\subsection{SpectralIndices}

The NDVI and NDWI diagrams (Figure 6) reveal the fact that the spectral response of the two sensors is almost identical; OMW areas are liquid in February and April (rich in vegetal substance of olive mill wastewater) and solid (dry) in August and October. Thus, the high values of NDWI correspond to the operation period between February and April.

In the following charts, the results of relative differences of spectral indices were evaluated. Concerning Sentinel-2, the NDVI, NDWI, and DI show high sensitivity values between OMW disposal sites and their neighborhood areas (the difference is greater than $30 \%$ ) for both study areas during February and April rather than August and October. PlanetScope imagery also shows equivalent responses compared to the Sentinel-2 results on both areas of study. Nonetheless, the calculated NDVI, NDWI, and DI revealed higher reflectance differences between each OMW site and its adjacent area during February and April (decreased in August and October).Thus, these are considered to be the optimum indices for enhancing the contrast between the inner and the outside parts of OMW disposal areas for both case studies. In addition, the sensitivity of PlanetScope seems to be more promising compared to Sentinel-2 (i.e., the difference of DI reaches 70\% for PlanetScope and $50 \%$ for Sentinel-2 in the Greek case study) (Figure 7). 

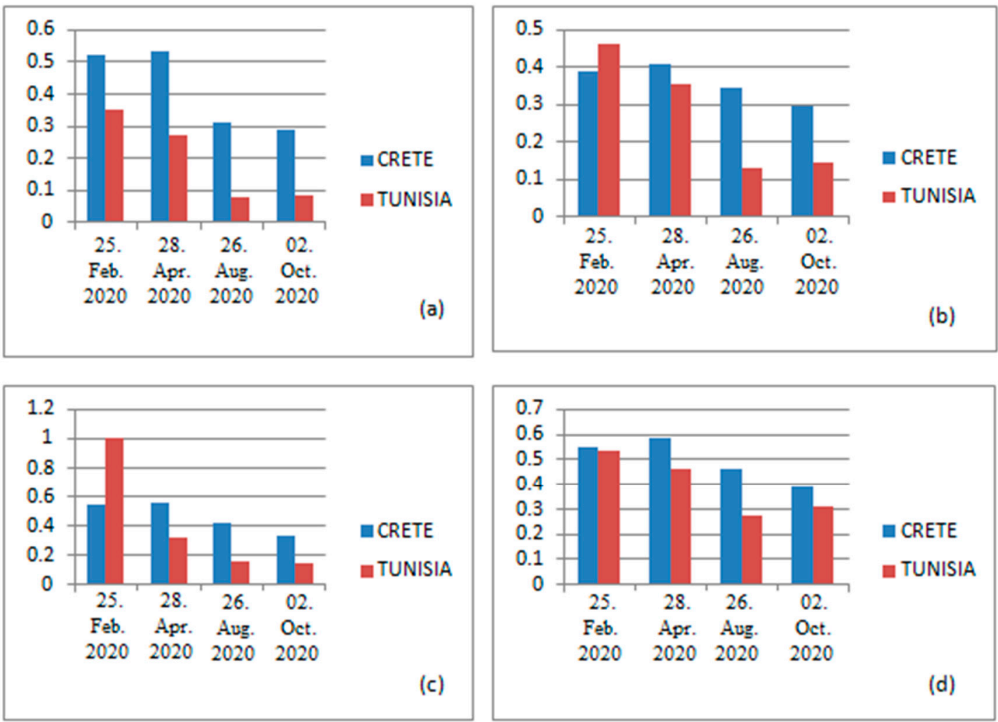

Figure 6. NDVI and NDWI mean values of OMW disposal sites for Tunisian and Greek studies areas; (a): NDVI mean values of wastes areas using Sentinel-2, (b): NDWI mean values of wastes areas using Sentinel-2, (c) NDVI mean values of wastes areas using PlanetScope, and (d): NDWI mean values of wastes areas using PlanetScope.
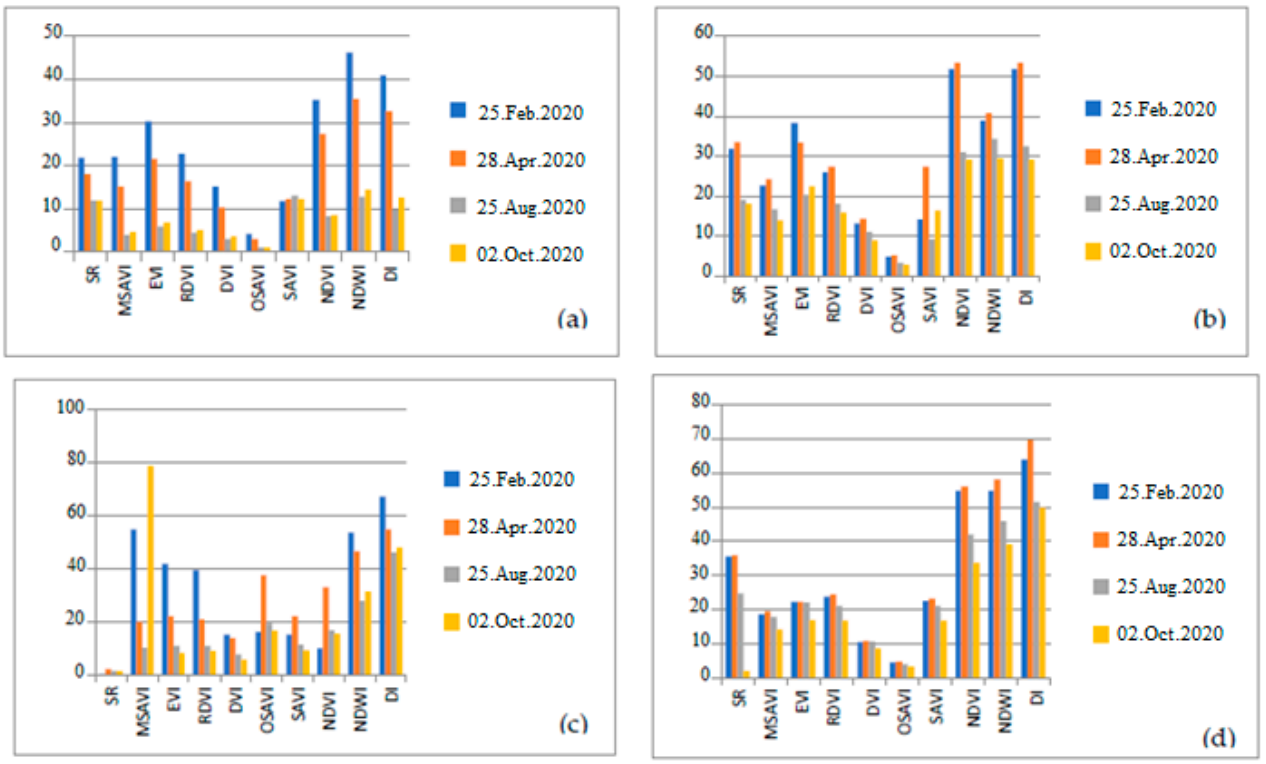

Figure 7. Spectral indices performance; (a): Sentinel-2 spectral indices performance for Tunisian study areas, (b): Sentinel-2 spectral indices performance for Greek study areas, (c): PlanetScope spectral indices performance for Tunisian study areas, (d): PlanetScope spectral indices performance for Greek study areas.

\subsection{Image Analysis Classification}

\subsubsection{Unsupervised Classification}

Regarding the case study in Tunisia, the ISODATA classification performed rather well in identifying OMW areas using both Sentinel-2 and PlanetScope data. This may be attributed to the smooth landscape morphology of the study area. Comparing results for both Composite 2 and Composite 3, the ISODATA classification algorithm seems to work better for Composite 3 in differentiating the OMW ponds from adjacent areas (i.e., residential areas). This applies for the ISODATA unsupervised classification in the Greek study area as well. Moreover, several false positive results were shown in different 
parts of Sentinel-2 images after applying the ISODATA algorithm. These may have been caused by the shadows on the images and the mountainous morphology in the vicinity of the OMW areas. At this stage, it seems that the use of Planetscope images is more effective for applying the ISODATA unsupervised classification to detect OMW areas and decrease false spectral responses compared to Sentinel-2 images. The results show that February is the best time period for differentiating the OMW ponds from its adjacent areas. This is due to the liquid wastes residue during this period [4].

Consecutively, Composite 3 seems to work better than Composite 1 and Composite 2 for both satellites' imagery and for both study areas. Therefore, Composite 3 was selected and used in the following classification analysis process. In fact, spatio-temporal changes in OMW areas, such as turning from a dry to liquid texture, influence the output of the ISODATA algorithm (Figures 8 and 9).

(a)

(c)

(e)

(g)
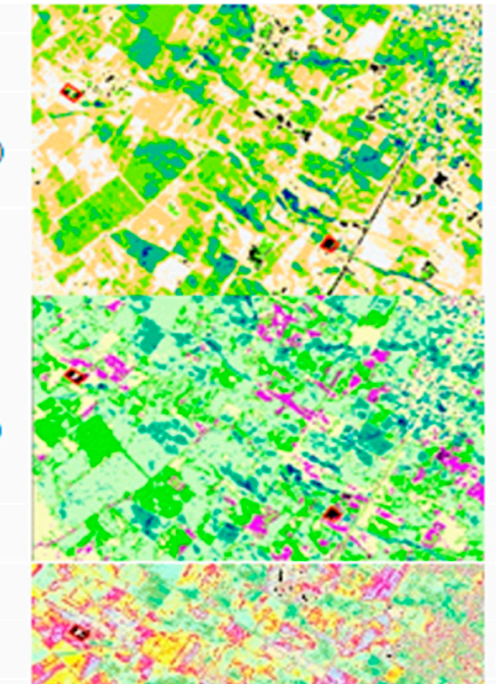

(i)

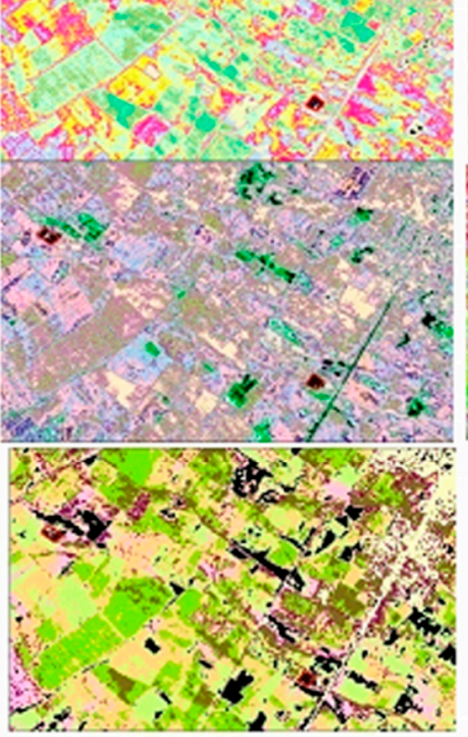

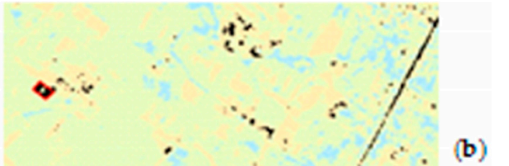

(b)

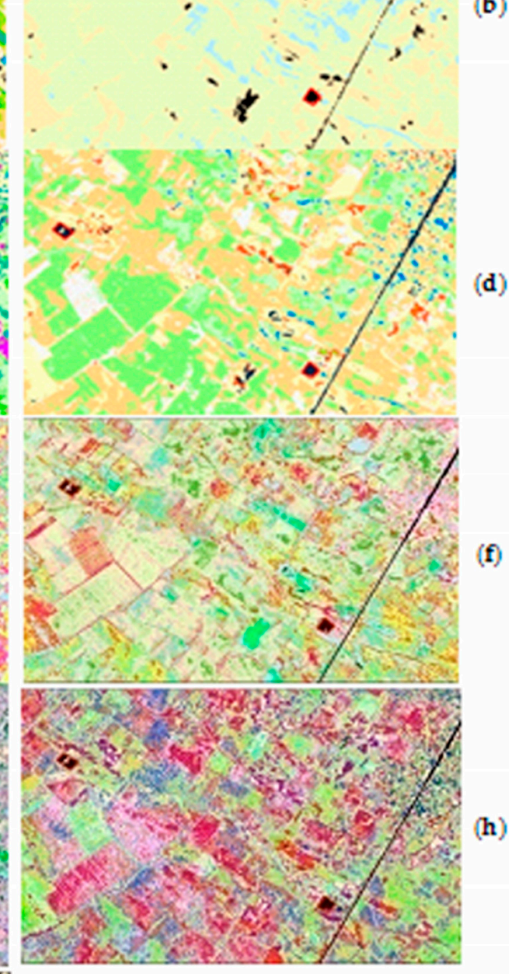

Figure 8. ISODATA classification for Tunisian study areas; (a): unsupervised classification using Sentinel-2 RGB image in February, (b): unsupervised classification using Sentinel-2 RGB image in August, (c): unsupervised classification using Sentinel-2 Composite 3 in February, (d): unsupervised classification using Sentinel-2 Composite 3 in August, (e): unsupervised classification using PlanetScope RGB image in February, (f): unsupervised classification using PlanetScope RGB image in August, (g): unsupervised classification using PlanetScope Composite 3 in February, (h): unsupervised classification using PlanetScope Composite 3 in August, (i): unsupervised classification using Sentinel-2 Composite 1 image in February; OMW disposal areas are indicated inside the red frame. 
(a)

(c)

(e)

(g)

(i)

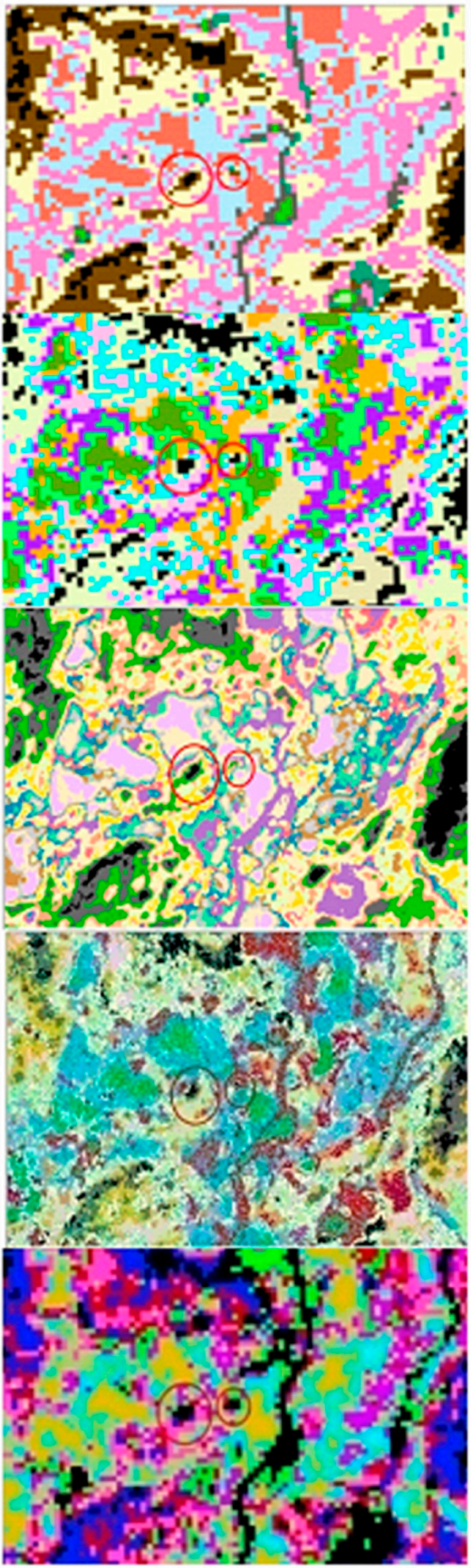

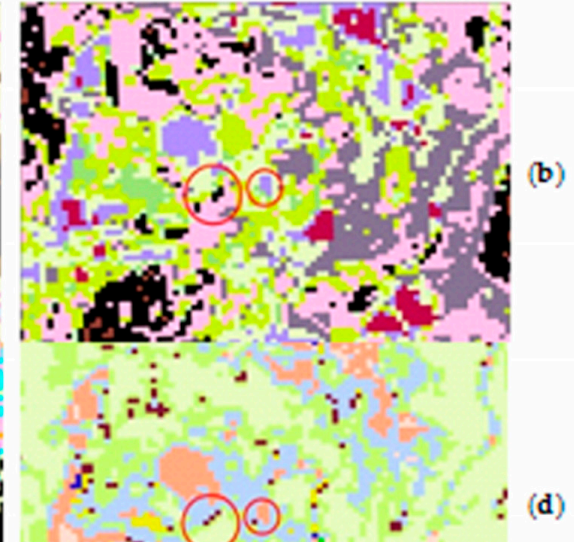

(d)

(f)

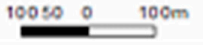

Figure 9. ISODATA classification for Greek study areas; (a): unsupervised classification using Sentinel-2 RGB image in February, (b): unsupervised classification using Sentinel-2 RGB image in August, (c): unsupervised classification using Sentinel-2 Composite 3 in February, (d): unsupervised classification using Sentinel-2 Composite 3 in August, (e): unsupervised classification using PlanetScope RGB image in February, (f): unsupervised classification using PlanetScope RGB image in August, (g): unsupervised classification using PlanetScope Composite 3 in February, (h): unsupervised classification using PlanetScope Composite 3 in August, (i): unsupervised classification using Sentinel-2 Composite 1 image in February; OMW disposal areas are indicated inside the red frame.

\subsubsection{Supervised Classification}

Apart from unsupervised classification, we further considered applying the maximum likelihood (ML) and the support vector machine (SVM) classifiers using ground truth data for validation. The application of the ML classification method for the case study of Tunisia showed promising results in detecting the OMW disposal areas using Sentinel-2 and 
PlanetScope, respectively (Figure 10). Once again, the results from satellite images acquired during February were more effective in differentiating OMW from all adjacent areas (such as roads) by using Composite 3. This can be attributed to the flat terrain morphology of the specific study area that assisted both medium- and high-resolution satellites to identify OMW disposal areas.

(a)

(c)

(e)

(g)
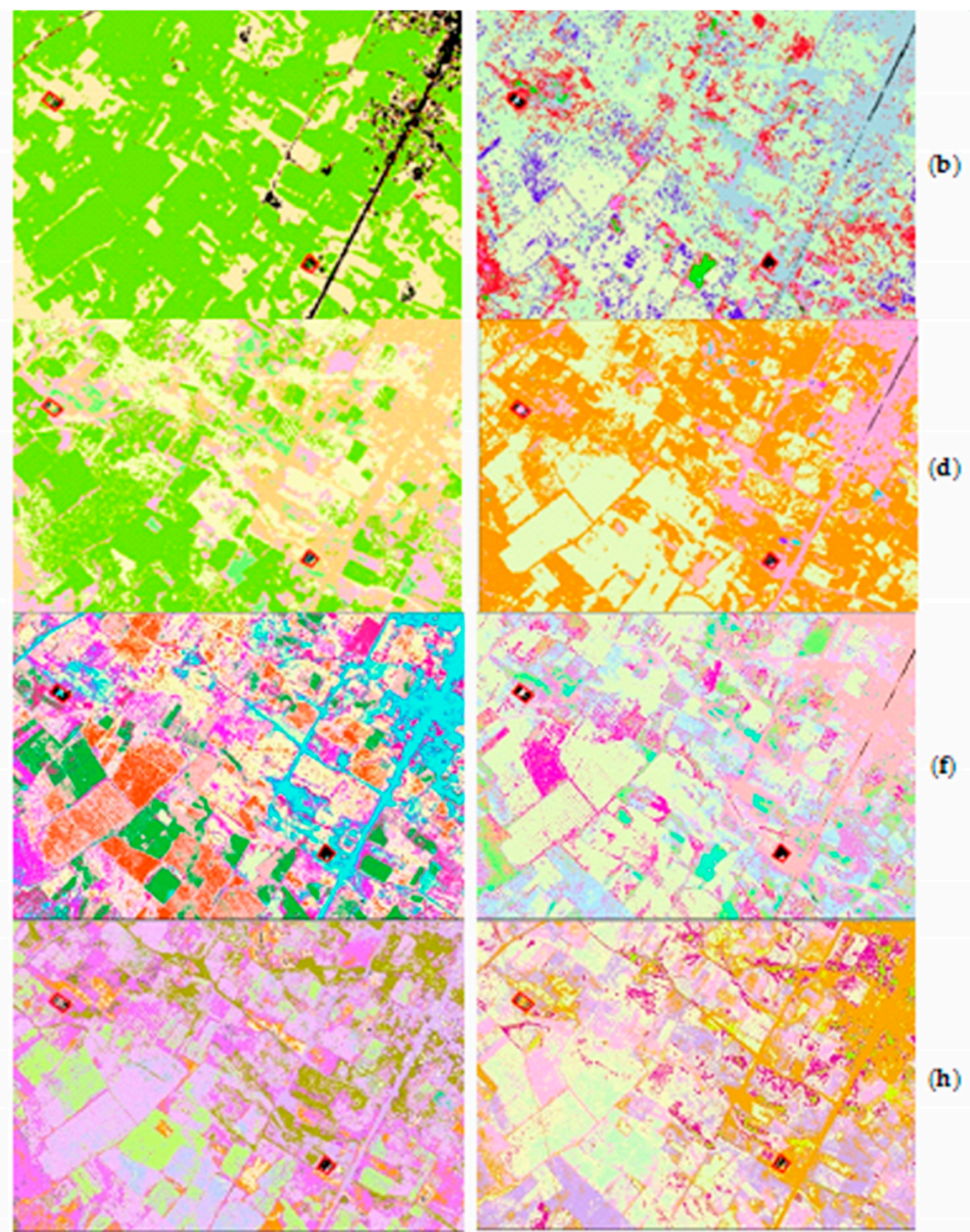

(d)

b)

(f)

(h)

Figure 10. Maximum likelihood classification for Tunisian study areas; (a): ML classification using Sentinel-2 RGB image in February, (b): ML classification using Sentinel-2 RGB image in August, (c): ML classification using Sentinel-2 Composite 3 in February, (d): ML classification using Sentinel-2 Composite 3 in August, (e): ML classification using PlanetScope RGB image in February, (f): ML classification using PlanetScope RGB image in August, (g): ML classification using PlanetScope Composite 3 in February, (h): ML classification using PlanetScope Composite 3 in August; OMW disposal areas are indicated inside a red frame. 
For the study area in Greece, results show that the ML classification was not able to detect OMW sites in both satellite images. This is probably due to its mountainous and complex morphology (Figure 11).

(a)

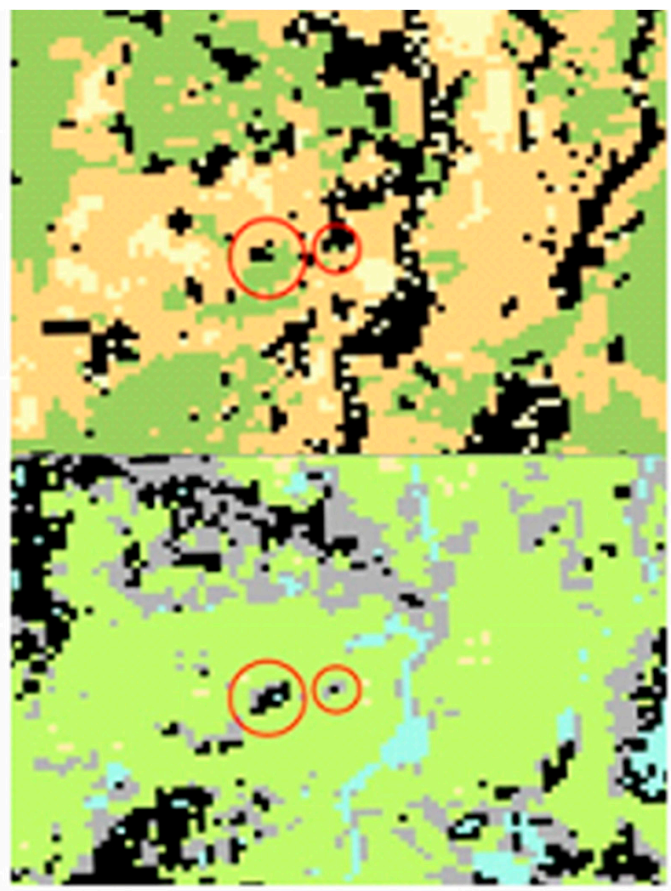

(e)

(g)

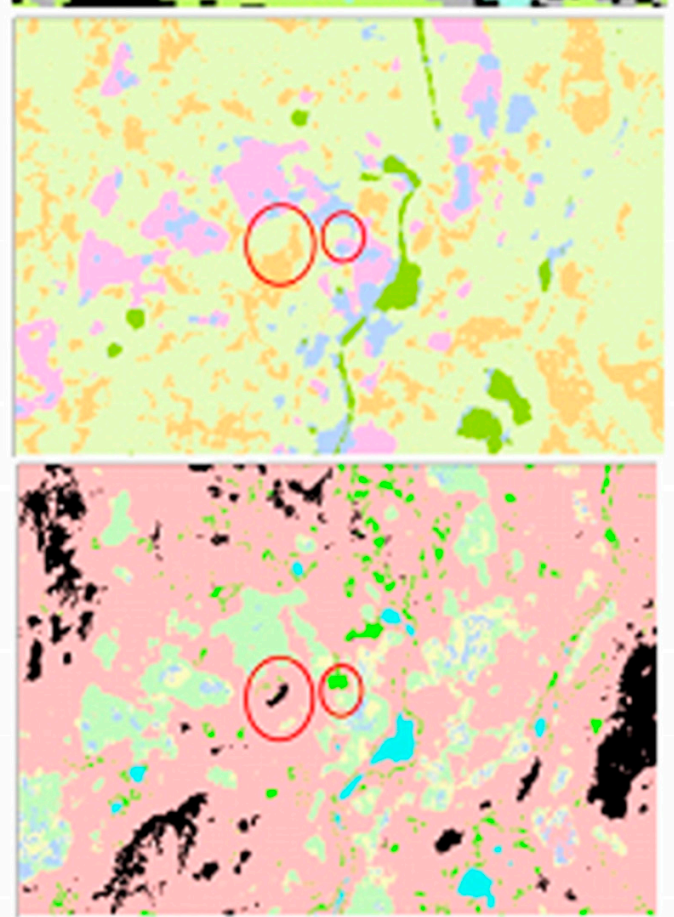

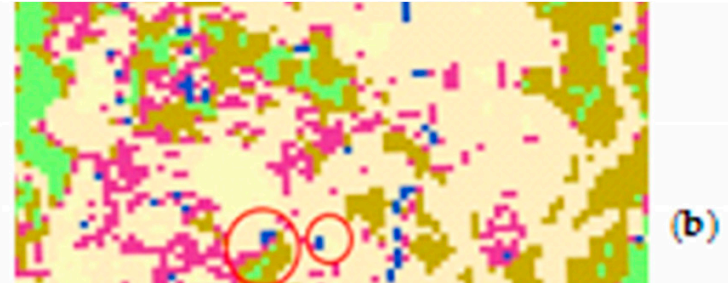

i $\tau_{i}=$
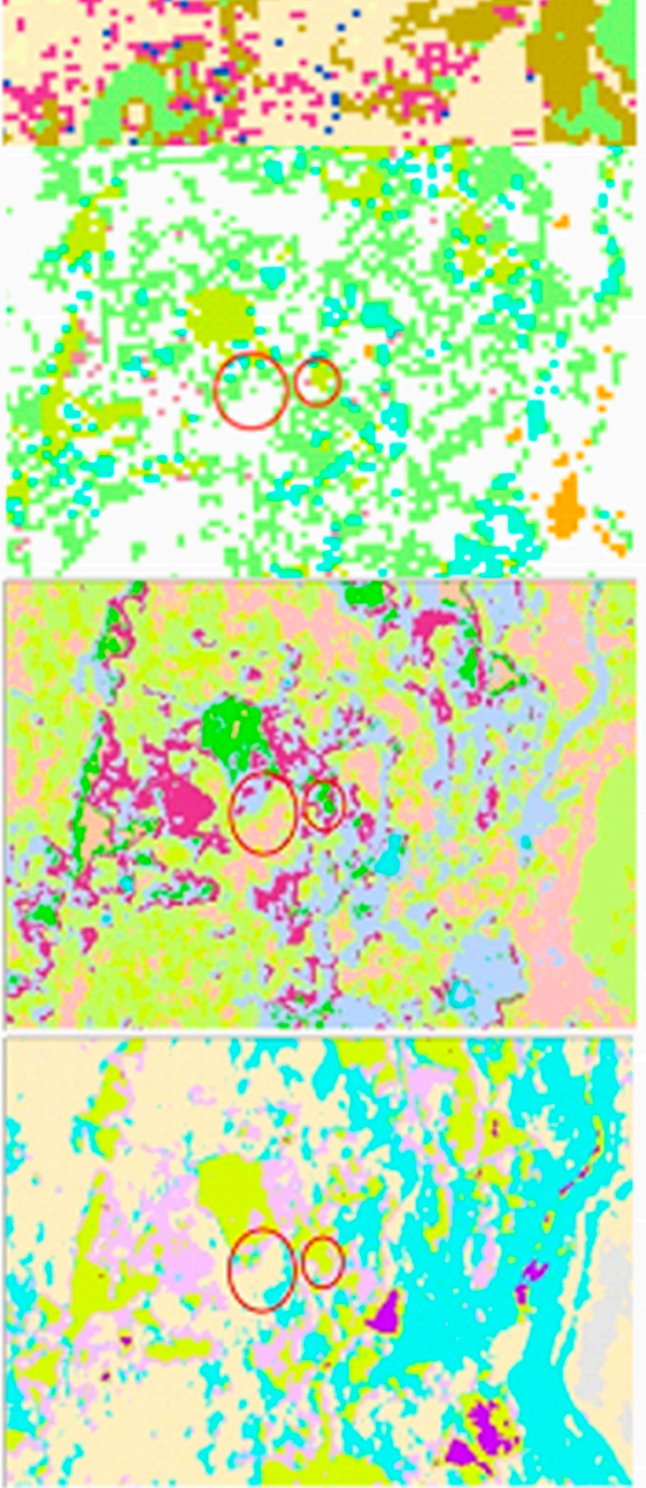

(d)

b)

(h)

Figure 11. Maximum likelihood classification for Greek study areas; (a): ML classification using Sentinel-2 RGB image in February, (b): ML classification using Sentinel-2 RGB image in August, (c): ML classification using Sentinel-2 Composite 3 in February, (d): ML classification using Sentinel-2 Composite 3 in August, (e): ML classification using PlanetScope RGB image in February, (f): ML classification using PlanetScope RGB image in August, (g): ML classification using PlanetScope Composite 3 in February, (h): ML classification using PlanetScope Composite 3 in August; OMW disposal areas are indicated inside the red frame. 
The SVM classification outputs yielded good results for both satellite images in the two case study areas, detecting OMW disposal areas especially when Composite 3 with images acquired during February was used. Specifically, as it is shown in Figure 12, the SVM algorithm produces better results when PlanetScope imagery is used for both areas.

(a)

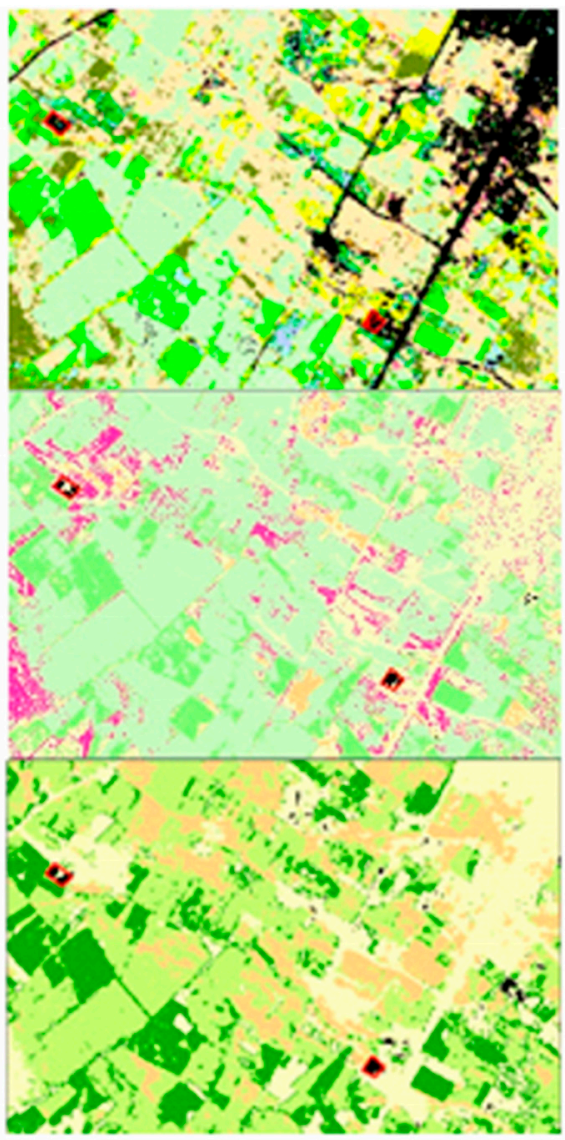

(e)

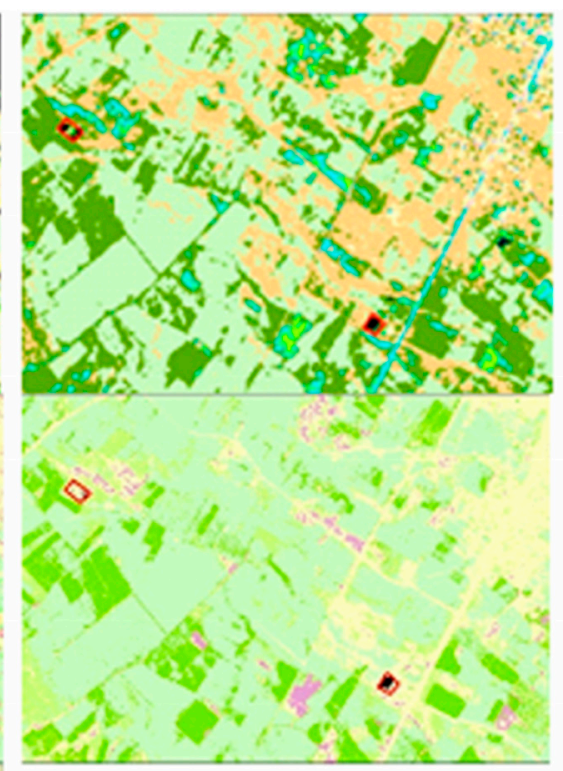

(b)

Figure 12. SVM classification for Tunisian study areas; (a): SVM classification using Sentinel-2 RGB image in February, (b): SVM classification using Sentinel-2 Composite 3 in February, (c): SVM classification using PlanetScope RGB image in February, (d): SVM classification using PlanetScope Composite 3 in February, (e): SVM classification using Sentinel-2 Composite 1 image in February. OMW disposal areas are indicated inside the red frame.

Concerning overall quantitative analysis, Kappa index was selected for evaluating the performance of the different classifiers [48]. It is a robust tool that can be estimated easily from the confusion (or error) matrix that is widely used in the classification accuracy assessment $[49,50]$.

A detailed scale was proposed by Sakiyama et al. [51], giving the degree of accordance linked to the kappa values. Kappa values inferior to 0.4 indicate a poor accordance and kappa values equal and superior to 0.4 indicate a good accordance. Consecutively, Table 6 shows that the SVM classification is the most efficient algorithm for detecting and differentiating OMW disposal areas; so, the kappa index value of 0.653 using Composite 3 of Sentinel-2 and the kappa index value of 0.604 using Composite 3 of PlanetScope images are computed for the case study of Tunisia, and kappa values of 0.571 for Sentinel-2 and 0.510 for PlanetScope were respectively compiled for the Greek area. This is followed by the ML classification using Composite 3 with a kappa value of 0.384 for Sentinel-2 and 0.295 for PlanetScope in the study area in Tunisia. The ISODATA classification becomes third. This highlights the fact that the SVM classifier provided the optimum results for both sensors and both case studies applied to Composite 3, using imagery acquired during February 2020. 
Table 6. Results of kappa index calculated for images acquired during February for different classification algorithms.

\begin{tabular}{cccc}
\hline Classification Algorithm & Satellite Sensor & Tunisian Study Area & Greek Study Area \\
\hline \multirow{2}{*}{ ISODATA } & Sentinel-2 & $\mathrm{SC}=0.246$ & - \\
& & $\mathrm{PCA}=0.394$ & $\mathrm{SC}=0.047$ \\
& PlanetScope & $\mathrm{SC}=0.154$ & $\mathrm{PCA}=0.190$ \\
$\mathrm{ML}$ & Sentinel-2 & $\mathrm{SC}=0.077$ & - \\
& & $\mathrm{PCA}=0.384$ & - \\
& PlanetScope & $\mathrm{SC}=0.134$ & $\mathrm{SC}=0.653$ \\
& & $\mathrm{PC}=0.295$ & $\mathrm{PCA}=0.571$ \\
SVM & Sentinel-2 & $\mathrm{PCA}=0.574$ & $\mathrm{SC}=0.618$ \\
& & $\mathrm{SC}=0.616$ & $\mathrm{PCA}=0.510$ \\
& PlanetScope & $\mathrm{PCA}=0.604$ &
\end{tabular}

\section{Discussion}

The study outcomes highlight the fact that low-cost remote sensing proved to be a powerful tool for effective monitoring of OMW ponds on a regional scale. In this study, different satellite image analysis algorithms were applied for: (a) enhancing the quality of image interpretation, (b) improving the quality of satellite images and (c) detecting and monitoring OMW areas. OMW spectral signatures were collected and the performance of various spectral indices was assessed in discriminating OMW disposal areas from surrounding areas during different time periods. In addition, detection and differentiation of OMW disposal sites from adjacent areas were also carried out by applying different vegetation indices and both unsupervised and supervised classification algorithms to various image composites. The final results were compared with images from the two satellite sensors, for both case studies and for various time periods in order to detect the ideal dataset and period for detecting OMW areas. Specifically, examination of spectral signatures concluded that the optimum bands for monitoring OMW are the NIR bands, represented by band 8 for Sentinel- 2 and band 4 for PlanetScope. In addition, the efficiency of NDVI, NDWI, and DI indices for monitoring OMW disposal areas for a spatial-temporal variable frame was highlighted and confirmed the role of the mentioned VIs by Alexakis et al. [4]. The application of different image analysis algorithms indicated that PCA analysis can be effectively used for mapping OMW ponds. Furthermore, the SVM classification algorithm showed optimum performance in differentiating and identifying OMW sites from neighbor areas, as it was proved by Agapiou et al. [16]. It is noteworthy to mention that, within our research, Composite 3 was used with images acquired during the winter period (February 2020). In addition, it was proved that the Tunisian case study, (with a more simplified terrain morphology), is a more suitable pilot area compared to the mountainous Greek case study.

Furthermore, the final results showed that the freely available satellite images of medium spatial resolution, such as Sentinel-2, can be efficiently used for monitoring OMW disposal areas. Although the performance of Planetscope images, in most cases, was better, the response of Sentinel-2 can be described as successful.

\section{Conclusions}

Remote-sensing techniques offer supplementary advantages compared to in situ observations and reduce the overall costs of environmental monitoring. The OMW disposal sites represent a vital environmental issue for the Mediterranean region and especially for the SidiBouzid region, (Tunisia) and the island of Crete, (Greece). The enormous amount of OMWs generated annually from olive oil production suggest that optimum treatment is an inevitable necessity.

This research highlights the use of satellite time-series imagery for monitoring OMW disposal sites in the Mediterranean region. The final results indicated that the integrated 
use of various image processing algorithms contribute significantly to OMW monitoring. The innovation of the specific work lays on the fact that for the very first time, satellite imageries of different spatial resolution (Sentinel-2 and PlanetScope) and corresponding image analysis algorithms are compared for their efficiency and applied in completely different landscape environments. The results indicate that, under certain circumstances, the freely distributed Copernicus data (Sentinel-2) can offer an optimum alternative in multi-temporal environmental surveillance. In this concept, the high-resolution satellite image data, such as PlanetScope, constitute an ideal solution for monitoring earth surface from space.

In the near future, the research team will carry out additional research in both study areas by using sampling and chemical analysis in order to associate olive mill wastewater spectral signatures with specific contaminant types. In addition, we plan to elaborate the use of $\mathrm{UAV} /$ drones in the overall research in order to improve substantially the spatial analysis of the acquired images.

Author Contributions: Conceptualization, W.I., D.D.A. and I.H.N.; methodology, W.I. and D.D.A.; software, W.I., D.D.A. and E.A.; validation, W.I., D.D.A., N.P. and M.H.I.; formal analysis, A.V.A.; investigation, W.I. and D.D.A.; resources, W.I., D.D.A. and A.V.A.; data curation, W.I., D.D.A. and A.V.A., writing - original draft, W.I., D.D.A., A.V.A., E.A., N.P., I.H.N. and M.H.I., writing review and editing, W.I., D.D.A., A.V.A., E.A., N.P., I.H.N. and M.H.I. supervision, D.D.A. and M.H.I. All authors have read and agreed to the published version of the manuscript.

Funding: This research received no external funding.

Conflicts of Interest: The authors declare no conflict of interest.

Availability of Data and Material: The data sets generated during and/or analyzed during the current study are available from the corresponding author on reasonable request.

\section{References}

1. Lopes, M.; Araujo, C.; Aguedo, M.; Gomes, N.; Gonçalves, C.; Teixeira, J.A.; Belo, I. The use of olive mill wastewater by wild type Yarrowialipolytica strains: Medium supplementation and surfactant presence effect. J. Chem. Technol. Biotechnol. $2009,84,533-537$. [CrossRef]

2. Doula, M.K.; Tinivella, F.; Sarris, A.; Kavvadias, V.; Moreno Ortego, J.; Komnitsas, K. Agricultural wastes: Protecting soil quality by sustainable disposal and reuse in agriculture. In Sustainability behind Sustainability; Antonis, Z., Ed.; Nova Science Publishers: Hauppauge, NY, USA, 2014; pp. 243-274.

3. Peikert, B.; Schaumann, G.E.; Keren, Y.; Bukhanovsky, N.; Borisover, M.; Garfha, M.A.; Shoqeric, J.H.; Dag, A. Characterization of top soils subjected to poorly controlled olive oil mill wastewater pollution in West Bank and Israel. Agric. Ecosyst. Environ. 2015, 199, 176-189. [CrossRef]

4. Alexakis, D.D.; Sarris, A.; Kalaitzidis, C.; Papadopoulos, N.; Soupios, P. Integrated use of satellite remote sensing, GIS and ground spectroscopy techniques for monitoring olive oil millwaste disposal areas in Crete Island-Greece. Int. J. Remote Sens. 2016, 37, 669-693. [CrossRef]

5. Paredes, M.J.; Moreno, E.; Ramos-Cormenzana, A.; Martinez, J. Characteristics of soil after pollution with wastewaters from olive oil extraction plants. Chemosphere 1987, 16, 1557-1564. [CrossRef]

6. Dellagreca, M.; Monaco, P.; Pinto, G.; Pollio, A.; Previtera, L.; Temussi, F. Phytotoxicity of low-molecular-weight phenols from olive mill wastewaters. Bull. Environ. Contam. Toxicol. 2001, 67, 352-359. [CrossRef] [PubMed]

7. Mansaray, A.S.; Dzialowski, A.R.; Martin, M.E.; Wagner, K.L.; Gholizadeh, H.; Stoodley, S.H. Comparing PlanetScope to Landsat-8 and Sentinel-2 for Sensing Water Quality in Reservoirs in Agricultural Watersheds. Remote Sens. 2021, 13, 1847. [CrossRef]

8. Rodis, P.S.; Karathanos, V.T.; Mantzavinou, A. Partitioning of olive oil antioxidants between oil and water phases. J. Agric. Food Chem. 2002, 50, 596-601. [CrossRef]

9. Bailey, A.R.; Clark, M.H.; Ferris, P.J.; Krause, S.; Strong, L.R. Solid waste disposal and recycling. In Chemistry of the Environment, 2nd ed.; Bailey, R.A., Clark, H.M., Ferris, J.P., Krause, S., Strong, R.L., Eds.; Academic Press: San Diego, CA, USA, 2002; pp. 769-792.

10. Hegazy, I.R.; Kaloop, R.M. Monitoring urban growth and land use change detection with GIS and remote sensing techniques in Daqahlia governorate Egypt. Int. J. Sustain. Built Environ. 2015, 4, 117-124. [CrossRef]

11. Rawat, J.S.; Kumar, M. Monitoring land use/cover change using remote sensing and GIS techniques: A case study of Hawalbagh block, district Almora, Uttarakhand, India. J. Remote Sens. Space Sci. 2015, 18, 77-84. [CrossRef]

12. Rao, P.; Zhou, W.; Bhattarai, N.; Srivastava, A.K.; Singh, B.; Poonia, S. Using Sentinel-1, Sentinel-2, and Planet Imagery to Map Crop Type of Smallholder Farms. Remote Sens. 2021, 13, 1870. [CrossRef] 
13. Messina, G.; Peña, J.M.; Vizzari, M.; Modica, G. A Comparison of UAV and Satellites Multispectral Imagery in Monitoring Onion Crop. An Application in the 'CipollaRossa di Tropea' (Italy). Remote Sens. 2020, 12, 3424. [CrossRef]

14. Hegazy, M.N.; Effat, H.A. Monitoring some environmental impacts of oil industry on coastal zone using different remotely sensed data. J. Remote Sens. Space Sci. 2010, 13, 63-74. [CrossRef]

15. El-Asmar, M.H.; Hereher, E.M.; El Kafrawy, B.S. Surface area change detection of the Burullus Lagoon, North of the Nile Delta, Egypt, using water indices: A remote sensing approach. J. Remote Sens. Space Sci. 2013, 16, 119-123. [CrossRef]

16. Agapiou, A.; Papadopoulos, N.; Sarris, A. Discriminant analysis of olive oil mill wastes using spectroradiometers in the visible and near infrared part of the spectrum. Eur. J. Remote Sens. 2015, 48, 793-809. [CrossRef]

17. Camarsa, G.; Gardner, S.; Jones, W.; Eldridge, J.; Hudson, T.; Thorpe, E.; Hara, E. Good Practice in Improving Environmental Performance in the Olive Oil Sector; Office for Official Publications of the European Union: Luxembourg, 2010.

18. Issaoui, W.; Aydi, A.; Mahmoudi, M.; Cilek, M.U.; Abichou, T. GIS based multi- criteria evaluation for Olive Mill Wastewater disposal site selection. Mater. Cycles Waste Manag. J. 2021, 23, 1490-1502. [CrossRef]

19. INS (Institut National de la Statistique). Données Générales sur la Population: Données Démographiques et Sociales. 2011. Available online: http:/ / www.ins.nat.tn (accessed on 20 November 2021).

20. Drusch, M.; Del Bello, U.; Carlier, S.; Colin, O.; Fernandez, V.; Gascon, F.; Hoersch, B.; Isola, C.; Laberinti, P.; Martimort, P.; et al Sentinel-2: ESA's optical high-resolution mission for GMES operational services. Remote Sens. Environ. 2012, 120, 25-36. [CrossRef]

21. Hadjimitsis, D.G. The Importance of Monitoring Urban Growth and Land-Cover Changes in Catchment Areas in Cyprus Using Multi-Temporal Remotely Sensed Data. Nat. Hazards Earth Syst. Sci. J. 2010, 10, 2235-2240. [CrossRef]

22. Agapiou, A.; Hadjimitsis, D.G.; Papoutsa, C.; Alexakis, D.D.; Papadavid, G. The Importance of Accounting for Atmospheric Effects in the Application of NDVI and Interpretation of Satellite Imagery Supporting Archaeological Research: The Case Studies of Palaepaphos and NeaPaphos Sites in Cyprus. Remote Sens. 2011, 3, 2605-2629. [CrossRef]

23. Chavez, P.S.; Berlin, G.L.; Sowers, L.B. Statistical Method for Selecting Landsat MSS Ratios. J. Appl. Photogramm. Eng. 1982, 8, 23-30.

24. Estornell, J.; Marti Gavilla, J.; Sebastia, M.; Mengual, J. Principal Component Analysis Applied to Remote Sensing. Model. Sci. Educ. Learn. 2013, 6, 83-89. [CrossRef]

25. Agapiou, A.; Papadopoulos, N.; Sarris, A. Monitoring olive mills waste disposal areas in Crete using very high resolution satellite data. J. Remote Sens. Space Sci. 2016, 19, 285-295. [CrossRef]

26. Mc Feeters, S.K. The Use of the Normalized Difference Water Index (NDWI) in the Delineation of Open Water Features. Int. J. Remote Sens. 1996, 17, 1425-1432. [CrossRef]

27. Jordan, C.P. Derivation of Leaf Area Index from Quality of Light on the Forest Floor. Ecolog 1969, 50, 663-666. [CrossRef]

28. Richardson, A.J.; Wiegang, C.L. Distinguishing Vegetation from Soil Background Information. Photogramm. Eng. Remote Sens. 1977, 43, 1541-1552.

29. Huete, A.R. A soil-adjusted vegetation index (SAVI). Remote Sens. Environ. 1988, 25, 295-309. [CrossRef]

30. Qi, J.; Chehbouni, A.; Huete, A.R.; Kerr, Y.H.; Sorooshia, S. A modified soil adjusted vegetation index. Remote Sens. Environ. 1994, 48, 119-126. [CrossRef]

31. Rondeaux, G.; Steven, M.; Baret, F. Optimization of soil-adjusted vegetation indices. Remote Sens. Environ. 1996, 55, 95-107. [CrossRef]

32. Richardson, A.; Everitt, J. Using spectral vegetation indices to estimate rangeland productivity. Geocarto Int. 1992, 1, 63-77. [CrossRef]

33. Liu, H.Q.; Huete, A.R. A feedback based modification of the NDV I to minimize canopy background and atmospheric noise. IEEE Trans. Geosci. Remote Sens. 1995, 33, 457-465. [CrossRef]

34. Huete, A.R.; Justice, C. MODIS vegetation index (MOD13) algorithm the oretical basis document, version 3. Univ. Ariz. 1999, 3, 295-309.

35. Huete, A.R.; Liu, H.Q.; Batchily, K.; Yan Leeuwen, W.A. Comparison of vegetation indices globalset of TM images for EOS-MODIS. Remote Sens. Environ. 1997, 59, 440-451. [CrossRef]

36. Jensens, J. Introductory Digital Image Processing: A Remote Sensing Perspective; Prentice-Hall PTR: Upper Saddle River, NJ, USA, 2005.

37. Richards, J.A. Remote Sensing Digital Image Analysis; Springer: Berlin/Heidelberg, Germany, 1986; p. 292.

38. Labovitz, M.L. Issues arising from sampling designs and band selection in discriminating ground reference attributes using remotely sensed data. Photogramm. Eng. Remote Sens. 1986, 52, 201-211.

39. Foody, G.M. The effects of viewing geometry on image classification. Int. J. Remote Sens. 1988, 9, 1909-1915. [CrossRef]

40. Campbell, J.B. Spatial correlation effects upon accuracy of supervised classification of land cover. Photogramm. Eng. Remote Sens. 1981, 47, 355-363.

41. Cristianini, N.; Shawe-Taylor, J. An Introduction to Support Vector Machines and Other Kernel-Based Learning Methods; Cambridge University Press: Cambridge, UK, 2000.

42. Dixon, B.; Candade, N. Multispectral Land Use Classification Using Neural Networks and Support Vector Machines: One or the Other, or Both. Int. J. Remote Sens. 2008, 29, 1185-1206. [CrossRef]

43. Paneque-Galveza, J.; Mas, J.; Moric, G.; Cristobald, J.; Martvneza, M.; Luza, A.; Gueze, M.; Macvae, M.; Reyes-Garcvaf, V. Enhanced Land Use/Cover Classification of Heterogeneous Tropical Landscapes Using Support Vector Machines and Textural Homogeneity. Int. J. Appl. Earth Obs. Geoinf. 2013, 23, 372-383. [CrossRef] 
44. Huang, C.; Davis, L.S.; Townshend, J.R.G. An assessment of support vector machines for land cover classification. Int. J. Remote Sens. 2002, 4, 725-749. [CrossRef]

45. Brown, M.; Lewis, H.G.; Gunn, S.R. Linear Spectral Mixture Models and Support Vector Machines for Remote Sensing. IEEE Trans. Geosci. Remote Sens. 2000, 38, 5. [CrossRef]

46. Melgani, F.; Bruzzone, L. Classification of Hyperspectral Remote Sensing Images with Support Vector Machines. IEEE Trans. Geosci. Remote Sens. 2004, 42, 8. [CrossRef]

47. Foody, G.M.; Mathur, A. A Relative Evaluation of Multiclass Image Classification by Support Vector Machines. IEEE Trans. Geosci. Remote Sens. 2004, 42, 6. [CrossRef]

48. Anthony, J.V.M.D.; Joanne, M.G. Understanding Interobserver Agreement: The Kappa Statistic. In From the Robert Wood Johnson Clinical Scholars Program; University of North Carolina: Chapel Hill, NC, USA, 2005.

49. Mashford, J.; Marlow, D.; Tran, D.; May, R. Prediction of sewer condition grade using support vector machines. J. Comput. Civ. Eng. 2010, 25, 283-290. [CrossRef]

50. Grinand, C.; Arrouays, D.; Laroche, B.; Martin, M.P. Extrapolating regional soil landscapes from an existing soil map: Sampling intensity, validation procedures, and integration of spatial context. Geoderma 2008, 143, 180-190. [CrossRef]

51. Sakiyama, Y.; Yuki, H.; Moriya, T.; Hattori, K.; Suzuki, M.; Shimada, K.; Honma, T. Predicting human liver microsomal stability with machine learning techniques. J. Mol. Graph. Modell. 2008, 26, 907-915. [CrossRef] 